\title{
Work related injury in New Zealand commercial
} fishermen

\author{
Alan E Norrish, P Colin Cryer
}

\begin{abstract}
The fatal and non-fatal injuries related to work in commercial fishermen operating out of $\mathrm{New}$ Zealand ports is described. Three data sources were used to provide information on the nature of the injuries sustained, as well as their circumstances. High rates of fatal and non-fatal injury were found, with most deaths attributed to drowning, and concerning a vessel operating in rough seas or poor weather. A higher fatal injury rate was found for the west coast of $\mathrm{New}$ Zealand when compared with the rest of the country. This is likely to be due to a combination of factors, including rougher sea conditions, a lower density of fishing vessels operating in the area, and the siting of many west coast fishing ports at dangerous river and harbour bars. Injuries to hands and fingers related to the use of winches, machinery and knives were common, as were back strains associated with lifting, and a variety of injuries resulting from falls. There is need for a comprehensive injury information source, such as an industry based register specific for fishing, so that effective preventative strategies and their evaluation can be developed.
\end{abstract}

Work-related injury is an important cause of morbidity and mortality for many groups in society. ${ }^{12}$ There are indications that commercial fishing is one of New Zealand's more hazardous occupations. Recent research by Cryer and Flemming ${ }^{1}$ has suggested that the rate and number of fatal injuries related to commercial fishing in New Zealand is high.

New Zealand has a small but important fishing industry, supplying domestic and export markets. In 1984, it occupied about 3200 commercial fishermen, and fish exports contributed $4.42 \%$ of New Zealand's total export earnings. ${ }^{3}$ Traditionally, it has been dominated by small fishing vessels $(<12$ metres in

Department of Community Health, Wellington School of Medicine, Wellington Hospital, Wellington, New Zealand

A E Norrish, P C Cryer length) working the inshore fishery. This is still the situation in the 1980s, although there has been an increasing trend towards larger vessels exploiting the deeper waters of the outer exclusive economic zone. ${ }^{4}$

In New Zealand, a survey of a sample of South Island commercial fishermen performed by the Department of Health in 1980, showed that these workers perceived their major work related injury problems to include back injuries, noise induced deafness, and penetration injuries from knives, fish spikes, and fish hooks. ${ }^{5}$

The combination of a cold, wet, and noisy working environment, long hours of work, and the social problems associated with prolonged periods away from home appeared to contribute greatly to work related health problems. Many of the injuries were attributed, at least in part, to the unstable working platform due to the constant movement of the boat.

A British study of fisherman over the period 196180 showed a high work related rate of fatal injury that caused concern in the United Kingdom. ${ }^{6}$ Other British studies $^{7-9}$ also indicated that deep sea trawler fishermen have a particularly high risk of morbidity and mortality resulting from injury related to work.

There has been little research to determine the size, nature, geographic distribution, or surrounding circumstances of the total (fatal and non-fatal) work related injury experience of commercial fishermen in New Zealand. The primary purpose of our study was to consider these issues.

\section{Methods}

Information on injuries related to work was from three data sources and in each case, injuries occurring to fishermen while travelling to and from work were excluded.

The data base for the fatal injuries was the same as that used by Cryer and Flemming. ${ }^{1}$ These data had been obtained from a number of sources and included fatal injuries occurring to fishermen operating out of New Zealand ports in the 10 year period 1975-84. Relevant cases were identified by their coding in the New Zealand Standard Classification of Occupations (NZSCO). ${ }^{10}$ This is a New Zealand adaptation of the International Standard Classification of Occupations. ${ }^{11}$ Occupational codes 6411-6419 


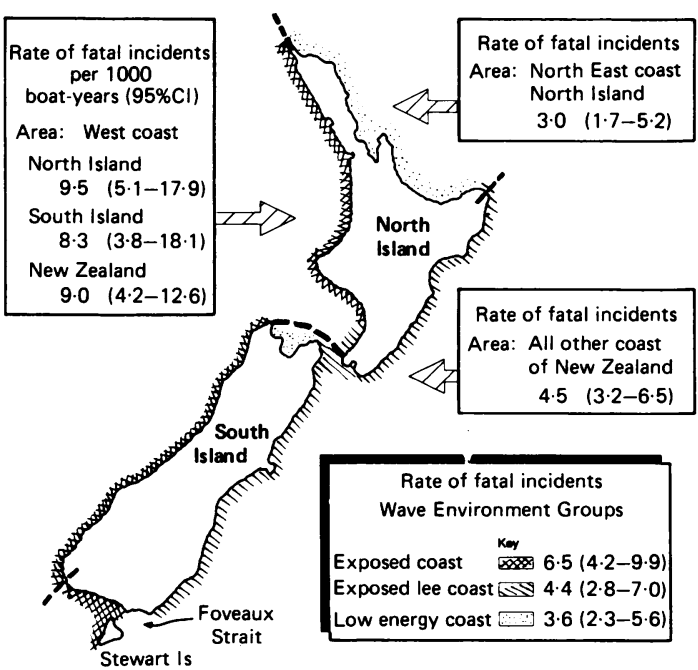

Figure 1 Work related fatal incidents by coastal area and wave environment areas, 1975-84. Wave environment areas were derived from New Zealand fisheries: a geographical perspective. ${ }^{4}$ Original source of information: Tortell P. New Zealand atlas of coastal resources. Wellington: Commission for the Environment, 1981.

were retrieved. This occupational group includes all those fishermen who go to sea in boats to catch fish, and does not include land-based workers such as process workers, fish farmers, and hatchery workers, who are exposed to different hazards. Two cases concerning overseas fishermen were excluded.

In view of the observation that most of the fatalities concerned an incident in which the fishing vessel was lost at sea, the distribution of fatalities around the New Zealand coastline was investigated by calculating rates for fatal incidents (rather than injuries) occurring in fishing vessels in various coastal areas. A fatal incident was defined as an event which led to the death of one or more fishermen at work, and this was expressed per 1000 boat-years. The geographical areas of interest included the west coasts of both islands, the north east coast of the North Island, and the remaining New Zealand coast (east coasts of both islands, and the south coast of the South Island). The coastline was also subdivided in an alternative manner, into "wave environment" areas according to the level of wave energy (see fig 1). The overall rates of fatal incidents for these various coastal areas were calculated, utilising denominator data from the 1980-1 New Zealand Census of Fishing ${ }^{12}$ on the port of domicile of New Zealand fishermen and vessels. Data for each coastal area were therefore derived from an aggregation of the data for the fishing ports situated within that area. An assumption was made that most of the fishing vessels operating in a particular area would be based at a local fishing port. This seemed reasonable given the knowledge that during $1974-84,85 \%$ of fishing vessels were small ( $<12$ metres in length), ${ }^{4}$ and for economic and practical reasons, usually operate around local coastlines.

The type of information available for each fatal incident determined how individual cases were assigned to a particular coastal area. The specific location of the fatal incident was identified in 34 of the total 56 fatal incident cases. In 16 cases, the base port for the vessel was stated, but in another six cases where this information was not available, the fishing port at or closest to the stated address of the vessel's owner was taken to represent the base port (most fishing vessels in New Zealand are owner operated or operate from the area in which the owner is domiciled). Two other cases were excluded from this part of the analysis as the site of the incident could not be definitely identified.

Information at discharge from hospital was obtained from the National Health Statistics Centre for all cases coded to water transport injuries (E codes $830-838)^{13}$ for the eight year period $1980-7$. Although this data source does not code cases to occupation, a rigorous exclusion process based upon examination of the descriptive data for occupation, injury circumstances, and location of injury contained on the data file, was undertaken to isolate all the cases likely to be commercial fishermen injured while performing their normal working duties. Cases were excluded where it was felt that any doubt existed. Readmissions and cases coded to those domiciled overseas were also excluded.

The third data source was the record of compensatable claims for injury for the 1987-8 financial year from the Accident Compensation Corporation (ACC). The ACC is a government body established to compensate victims of personal injury by accident, as well as to promote the rehabilitation and the prevention of unintentional injury. This group includes all work related injuries that occurred to fishermen coded to NZSCO codes 6411-19 where a claim to the ACC had been compensated, and may be expected to include some overseas fishermen as they were not identifiable within the data file. Only injuries leading to a compensated claim are included (usually those that had resulted in more than one week off work). Descriptive information such as exists for fatalities and cases that were in hospital is not available for this source. The coding system used provided a reasonable classification of diagnosis of injury and the associated cost in most cases. It proved difficult to quantify the circumstances of the injuries, however, due to the low specificity of many coding categories in the ACC system.

In generating rates of injury by age group (for all three data sources), denominator populations of fishermen for each year were derived by linear extrapolation and interpolation from the New 
Table 1 Age specific and total rates of work related injuries for New Zealand commercial fishermen

\begin{tabular}{llll}
\hline & \multicolumn{3}{l}{ Age specific incidence rate per 1000 a year $(95 \% C I)$} \\
\cline { 2 - 4 } & & $\begin{array}{l}\text { Injury requiring } \\
\text { hospital treatment } \\
\text { Fatal injury } \\
\text { Age }\end{array}$ & $\begin{array}{l}\text { ACC } \\
\text { compensated } \\
\text { injury } \\
1975-84\end{array}$ \\
Group $(y)$ & $(n=79)$ & $154)$ & $\begin{array}{l}1988 \\
(n=307)\end{array}$ \\
\hline $15-24$ & $3 \cdot 0(2 \cdot 0-4 \cdot 7)$ & $5 \cdot 6(4 \cdot 0-8 \cdot 0)$ & $103(82-129)$ \\
$25-34$ & $3 \cdot 2(2 \cdot 2-4 \cdot 6)$ & $6 \cdot 2(4 \cdot 7-8 \cdot 2)$ & $111(93-133)$ \\
$35-44$ & $2 \cdot 1(1 \cdot 3-3 \cdot 4)$ & $6 \cdot 5(4 \cdot 8-8 \cdot 7)$ & $109(90-132)$ \\
$45-54$ & $1 \cdot 5(0 \cdot 7-3 \cdot 0)$ & $5 \cdot 7(3 \cdot 8-8 \cdot 5)$ & $98(74-129)$ \\
$55-64$ & $3 \cdot 3(1 \cdot 5-7 \cdot 1)$ & $5 \cdot 4(2 \cdot 9-10 \cdot 3)$ & $58(33-101)$ \\
Total & $2 \cdot 6(2 \cdot 1-3 \cdot 3)$ & $6 \cdot 0(5 \cdot 1-7 \cdot 0)$ & $104(94-116)$ \\
\hline
\end{tabular}

Zealand Census of Populations and Dwellings data for the years 1976, 1981, and 1986.

The standard $\chi^{2}$ test for a $2 \times \mathrm{r}$ contingency table was used to compare rates, and $95 \%$ confidence intervals (CIs) were generated using a Hewlett-Packard HP41-C programmable calculator (program PRPLIM-based on program 15 in Rothman and Boice $\left.^{14}\right)$. The programmable calculator was also used for trend analysis for proportions where appropriate, using program Trend, which is based on Program 19 in Rothman and Boice. ${ }^{14}$

\section{Results}

Table 1 shows the age specific and overall rates of fatal injuries, injuries that required treatment in hospital, and ACC compensated claims injuries. Most workers in the fishing industry are men. Because of the small numbers of women injured (one fatality, no hospital cases, five ACC compensated), no sex specific incidence rates for injury were generated.

\section{WORK RELATED FATAL INJURY}

Seventy nine cases of fatal injury were found giving a rate for New Zealand of 2.6 per 1000 fishermen a year. Seventy four $(94 \%)$ of these occurred at sea, and virtually all were due to drowning. Generally the sea and weather conditions were poor, with heavy seas specifically mentioned in $39 \%$ and large or freak waves in another $22 \%$. The fisherman fell or was washed over the side of the vessel in $13 \%$ of cases. In most cases $(78 \%)$ the vessel foundered (filled with water and sank) and of these, the boat capsized in $27 \%$. Although the specific activity just before the fatal event was not specified in $33 \%$ of cases, another $30 \%$ mentioned lifting nets or lobster pots, and $15 \%$ of boats were either heavily laden or returning to port at the time.

Figure 1 shows the geographical distribution of fatal incidents around the New Zealand coastline. Table 2 gives the results of significance tests for these rates of fatal incident by coastal area. The usefulness of these findings is limited by small numbers, and assumptions that had to be made in linking the base port of the vessel with the scene of the fatal incident. The results indicate, however, that increased rates of fatal incidents occurred on the west coast of New Zealand. Significance tests also suggested that the north eastern coastline of the North Island may be a relatively safer region, with fatal injury rates only one third those of the west coast regions.

When the fishing ports were categorised by wave environment, differences were found between the rates for the high and low wave energy areas. The difference observed between the exposed coast and the rest of New Zealand was almost significant $(p=$ 0.06 ). A trend within this categorisation was evident with higher rates for those areas of greater coastal wave intensity $\left(\chi^{2}=3.59, \mathrm{df}=1, \mathrm{p}=0.06\right) .{ }^{14}$

\section{INJURIES REQUIRING TREATMENT IN HOSPITAL}

The 154 cases of injury that required treatment in hospital gave an estimated rate of 6.0 per 1000 fishermen a year. An overall decrease was found in the rate of fishermen needing treatment in hospital from 1980 to 1987 . This was statistically significant (trend analysis ${ }^{14} ; \chi^{2}=4 \cdot 81, \mathrm{df}=1, \mathrm{p}=0 \cdot 03$ ).

Table 3 lists the most common circumstances leading to injury, and fig 2 outlines diagnostic groups

Table 2 Fatal incident rates by geographical area and wave environment area

\begin{tabular}{|c|c|c|c|c|c|}
\hline Area & Incidence & Rate (per 1000 boat-years) & $\chi^{2 \star}$ & $d f$ & p-Value \\
\hline $\begin{array}{l}\text { Geographical area: } \\
\text { West coast, North Island } \\
\text { West coast, South Island } \\
\text { West coast, New Zealand } \dagger \\
\text { North-east coast, North Island } \\
\text { All other coast of New Zealand }\end{array}$ & $\begin{array}{r}9 \\
6 \\
15 \\
12 \\
28\end{array}$ & $\begin{array}{l}9 \cdot 5 \\
8 \cdot 3 \\
9 \cdot 0 \\
3 \cdot 0 \\
4 \cdot 5\end{array}$ & $\begin{array}{l}5 \cdot 54 \\
2 \cdot 41 \\
8 \cdot 41 \\
3 \cdot 78 \\
0 \cdot 02\end{array}$ & $\begin{array}{l}1 \\
1 \\
1 \\
1 \\
1\end{array}$ & $\begin{array}{l}0.02 \\
0.12 \\
0.004 \\
0.05 \\
0.88\end{array}$ \\
\hline $\begin{array}{l}\text { Wave environment area: } \\
\text { Exposed coast } \\
\text { Exposed lee coast } \\
\text { Low energy coast }\end{array}$ & $\begin{array}{l}21 \\
17 \\
18\end{array}$ & $\begin{array}{l}6 \cdot 5 \\
4 \cdot 4 \\
3 \cdot 6\end{array}$ & $\begin{array}{l}3 \cdot 46 \\
0 \cdot 05 \\
2 \cdot 11\end{array}$ & $\begin{array}{l}1 \\
1 \\
1\end{array}$ & $\begin{array}{l}0.06 \\
0.83 \\
0.15\end{array}$ \\
\hline
\end{tabular}

$\mathrm{n}=56$ incidents (75 injuries).

${ }^{\star}$ Mantel-Haenszel $\chi^{2}$ test compares area of interest with the remaining areas for the whole of New Zealand; $\chi^{2}$ test for trend analysis ${ }^{14}$ of wave environment areas was also performed $\left(\chi^{2}=3 \cdot 59, \mathrm{df}=1, \mathrm{p}=0.06\right)$.

+West coast, New Zealand incorporates west coast, North Island and west coast, South Island. 
Table 3 Major causes of hospitalised injuries occurring to New Zealand commercial fishermen (1980-87)

\begin{tabular}{lr}
\hline Cause of Injury & Incidence $(\%)$ \\
\hline Equipment/machinery on vessel: & \\
Cables, chains, ropes, fishing tackle, anchor & $30(19 \cdot 5)$ \\
Winches, pulleys & $19(12 \cdot 3)$ \\
Falling objects, full nets & $12(7 \cdot 8)$ \\
Other machinery & $6(3 \cdot 9)$ \\
Total & $67(43 \cdot 5)$ \\
Vessel: & \\
Vessel-total loss & $9(5 \cdot 8)$ \\
Explosion & $6(3 \cdot 9)$ \\
Fire & $5(3 \cdot 2)$ \\
Collision (other vessel/wharf) & $5(3 \cdot 2)$ \\
Hatch/loading door & $5(3 \cdot 2)$ \\
Thrown against vessel by wave & $4(2 \cdot 6)$ \\
Vessel structure-other & $7(4 \cdot 5)$ \\
Total & $41(26 \cdot 4)$ \\
Falls: & \\
Same level (on deck) & $9(5 \cdot 8)$ \\
Different levels (on board) & $8(5 \cdot 2)$ \\
Overboard & $6(3 \cdot 9)$ \\
Into holds & $6(3 \cdot 9)$ \\
Boarding/disembarking & $3(1 \cdot 9)$ \\
Fall-not specified & $5(3 \cdot 2)$ \\
Total & $37(23 \cdot 9)$ \\
Other unspecified cause & $9(5 \cdot 8)$ \\
\hline
\end{tabular}

for the injuries along with the average durations of stay in hospital. One hundred and forty five (94\%) injuries occurred on board fishing vessels. The use of equipment or machinery was an important cause of injury. Almost one third of the injuries were caused while handling ropes, cables, or chains or while operating winches. Injuries, mainly to upper limbs, resulted from fishermen being entrapped in winches, ropes, and pulleys. Injuries were also sustained when fishermen were struck by ropes, either breaking and whipping back, or snapping suddenly across the deck. This caused a variety of head, trunk, and limb lacerations, contusions, and fractures. Falling objects, including boxes of fish and loaded nets caused mainly crushing and head injuries.

Forty one cases were a result of events directly

\section{Frequency of injury}

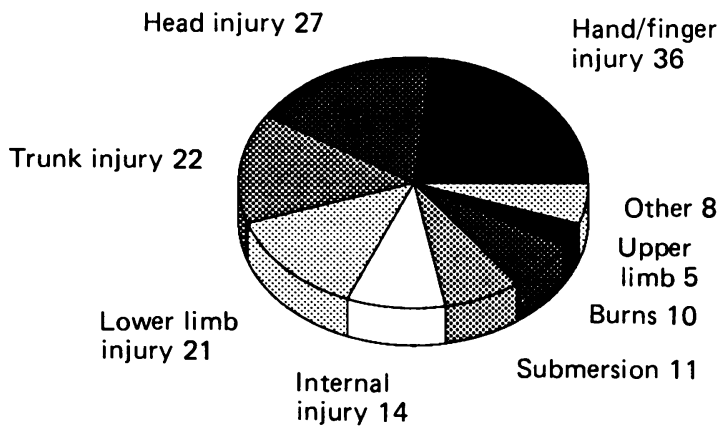

related either to the vessel (including its total loss, collisions, and fires or explosions) or parts of its structure such as being caught in closing hatch covers and thrown against the superstructure by large waves.

One quarter of the injuries were due to falls either from slipping over on deck, or from falling from one level of the vessel to another, such as into holds. Some injuries occurred while boarding or disembarking. Injuries caused by falls included fractures, especially of the lower limbs and ribs, head injuries, and internal injuries. Injuries to the lower limbs, while only the fourth most common diagnostic group, nevertheless incurred the highest total, and longest average stay in hospital ( 11.6 days).

\section{ACC COMPENSATED INJURY}

During the 12 months studied, 307 claims to the ACC were compensated, giving a relatively high injury rate of 104 per 1000 fishermen a year. Figure 3 shows the most common types of injury group compensated and indicates the level of ACC costs incurred.

One hundred and thirty nine of the 307 cases were diagnosed as strains or sprains. Back strain (87 cases) represented almost two thirds of these and $28 \%$ of the total injuries. This agrees with the finding that over one third of the injuries (121 cases) were recorded as having occurred during lifting, lowering, loading, or unloading, and boxes (probably containing fish in many cases) were specified in 28 of these. The compensation for back strain injuries was $36 \%$ of the total cost, and indicates the importance of this injury group. Strains of the knees, shoulders, and forearms were also common.

The second most common diagnostic group were fractures. Half of these concerned the hand or fingers, which were also the most common parts to be lacerated or superficially injured. Over one third of lacerations and superficial injuries became infected,

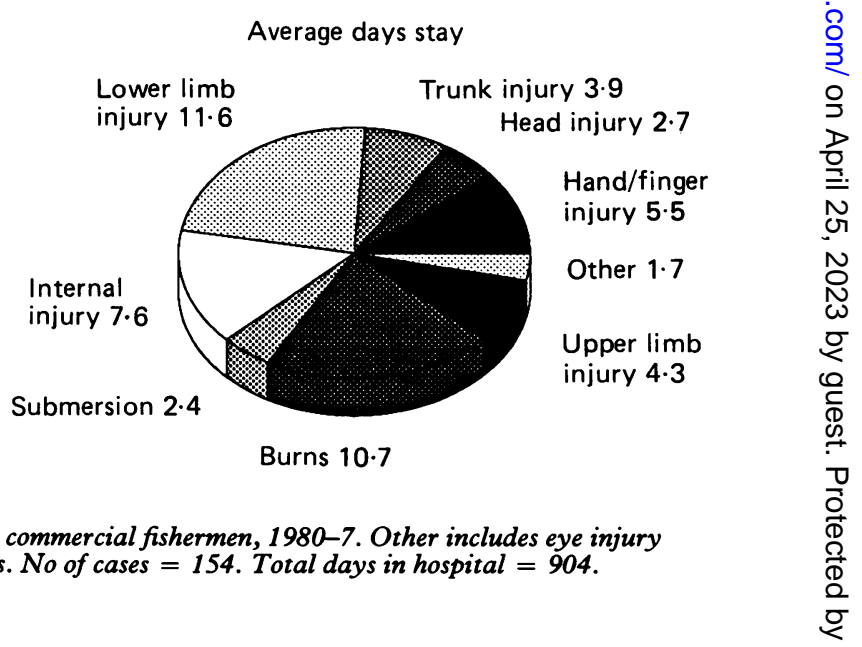

Figure 2 Injuries requiring hospital treatment for New Zealand commercial fishermen, 1980-7. Other includes eye injury (three cases). Upper limb injury excludes hand and finger injuries. No of cases $=154$. Total days in hospital = 904 . 
Injury frequency

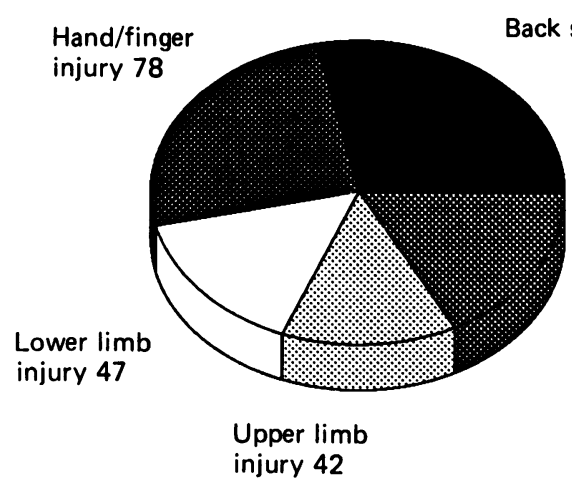

Total cost (approx $\$ N Z$ )

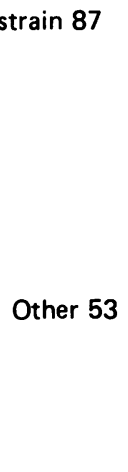

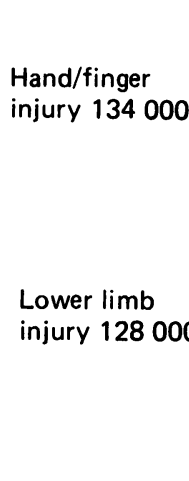

Back strain 303000

Figure 3 ACC Compensated injuries for New Zealand commercial fishermen, 1988. No of cases $=307$. Upper limb injury excludes hand and finger injuries.

reflecting another hazard of the fishing workplace. Injuries to the hands and fingers made up $78(25 \%)$ of the cases. Operating machinery (including winches) in 35 cases, and the use of knives ( 13 cases specified) were frequently associated with these hand injuries.

\section{Discussion}

This study has shown high rates and numbers of fatal injuries, injuries requiring treatment in hospital, and ACC compensated injuries for commercial fishermen in New Zealand.

In considering the injury rates identified in this study, it is necessary to point out that some misclassification bias may occur in either direction due to different sources being used for numerator and denominator populations. This is not, however, expected to be large for the fatal injuries and ACC claims data. For the injuries requiring treatment in hospital, the rigorous exclusion process undertaken in the course of case determination is likely to have led to an underestimation of the true numbers.

It should also be noted that while the three data sources may be expected to provide a gradient of severity of injury, they are not mutually exclusive and individual cases may occur in one or more of the data sources.

The fatal injury rate of 2.6 per 1000 fishermen a year over the 10 year period was the sixth highest in New Zealand, behind a number of high risk but numerically small occupational groups such as agricultural helicopter pilots and demolition labourers. The total number of 79 deaths was second only to the large farming occupational group.

Most of these fatal injuries occurred offshore as a result of the fishing vessel foundering, often in bad weather or heavy seas. Analysis of the distribution of fatal incidents around the New Zealand coastline indicates a threefold increase in fatal incident rates occurring on fishing vessels operating out of ports on the west coast compared with the lowest on the north east coast of the North Island. It is tempting to attribute this finding to rougher sea conditions in this region. Further analysis of the ports of domicile, however, graded according to the intensity of wave environment, showed only a small increase in rate for the roughest region, which also included the Foveaux Strait and Stewart Island fisheries along with the west coast. In view of this, it is likely that at least two other factors are important in determining the rates for the west coast fishery. These include the predominance of west coast fishing ports sited at river mouths or harbours, with bars which become extremely hazardous to cross in adverse weather, and a factor relating to the density of fishing vessels working in an area. Most incidents where fishing vessels founder or capsize at sea are attended for rescue purposes by other fishermen working in the area (Marine Division, Ministry of Transport, personal communication), and thus higher density fisheries such as Foveaux Strait may be considered to be relatively safer despite the higher wave intensities in that area.

Our study also suggests that a fatal injury was more likely to occur during certain activities such as pulling up nets or lobster pots, or when the vessel was heavily laden and heading back to port. These observations are consistent with the knowledge that these factors, by changing the forces operating, may reduce the stability of the vessel in the water. They apply particularly to smaller vessels.

Practical and economic constraints also mean that smaller vessels are often undermanned, resulting in very long hardworking periods often without adequate sleep. Unfortunately, because of data limitations, this study was unable to relate injuries to the type of fishing engaged in, the size of the vessel, 
the level of manning, or to the time that the vessel had been at sea; the potential significance of these factors can, therefore, only be surmised. It is considered important that such information be collected in the future. This is particularly so in view of the trend towards fishermen working on large vessels with large crews and often extensive on board fish processing that has occurred over recent years in this country. ${ }^{4}$ The possible advantages of fishing from large vessels for risk reduction, arise from higher manning levels, a more stable working platform, and opportunities to institute training and safety measures such as those promoted by the Fishing Industry Board for deep sea trawlers. ${ }^{1516}$ The decrease in rate of injuries requiring treatment in hospital during 1980-7 may reflect these changes in the type of vessel; countered against these, are the increased periods spent at sea, and evidence from British studies that show high rates of injury on deep sea trawlers. ${ }^{679}$

Although there are limitations in drawing comparisons between the British and New Zealand situations, it should be noted that the local fatal injury rate of 2.6 per 1000 a year is significantly higher than the British rates for all fishermen found by Reilly ${ }^{6}$ (1.67 per 1000 for $1961-70$, and 1.70 per 1000 for $1971-$ 80), but not as high as the highest rate (3.21 per 1000 for 1971-80) for deep sea fishermen.

The ACC compensated claims injury rate indicates that one in 10 commercial fishermen suffered an injury requiring at least one week off work in the 1987-8 financial year. Discussion with representatives of the fishing industry would suggest that this rate, although high, may well be a significant underestimation of the true rate of injury normally considered to give rise to this degree of disability. Fishermen, especially those in self employed and owner operator situations, have a reputation for attempting to work through many injuries if possible, to avoid having to lay up the vessel and the other workers.

There are few other occupational groups with which to compare such rates in New Zealand. A study of forestry workers for 1984 showed a much higher New Zealand hospital discharge rate of 20 per 1000 per year (PC Cryer, K Ehrman, unpublished observations). This group had a slightly higher ACC compensated claims rate compared with the fishermen but a considerably lower fatal injury rate of 0.8 per 1000 a year. The comparison of these two reputedly dangerous occupations therefore, emphasises the importance of a high fatal to non-fatal injury ratio for fishermen.

Both the hospital discharge and ACC-compensated claims data suggest similar predisposing circumstances for injury. These include working with winches, ropes, and machinery, lifting boxes of fish, handling knives and fish spikes, and falls. Despite the relatively unavoidable factors already mentioned such as the weather and sea conditions and the heavy manual nature of the work, many of these injuries are likely to be preventable within the reality of reasonable economic and practical constraints. It is not the purpose of this paper to speculate upon possibilities for the development of preventive strategies, although the development of proactive interventions by and for those concerned with the fishing industry is obviously the desirable outcome in the longer term. It has already been mentioned, however, that existing data sources are inadequate to complete the picture describing the major factors causing injury. In addition to those factors relating to the nature of fishing and the vessel, other important factors pertaining to the individual worker such as experience, fitness, fatigue, use of safety equipment, and the contribution of alcohol and drugs, are currently not documented in New Zealand. Limited investigations into the effects of work stress on fishermen have been conducted in Norwegian ${ }^{17}{ }^{18}$ and Polish ${ }^{19}$ studies, but possible relations with work related injury were not examined.

In order for more progress in prevention of injury to be made in the face of the changing nature of the fishing industry, an effective register of work related injuries needs to be established.

We acknowledge and thank Dr John Langley for his helpful comments on an earlier draft of this paper; the Accident Compensation Corporation of New Zealand for funding and access to data; the New Zealand Fishing Industry Board for their interest and assistance; and the National Health Statistics Centre of the Department of Health for willing cooperation in accessing relevant data sources.

The opinions, findings, and conclusions expressed herein are the views of the authors, and do not necessarily reflect those of the sponsor.

1 Cryer PC, Flemming C. A review of work-related fatal injuries in New Zealand 1975-84 numbers, rates and trends. New Zealand Medical Journal 1987;100:816, 1-6.

2 Baker SP, O'Neill B, Karpf RS. The injury fact book. Lexington: Lexington Books, 1984:7-15, 50-1.

3 Department of Statistics. New Zealand official year book. 89th ed. Wellington: Department of Statistics, 1984.

4 Boyce AG, Martin DE, Stringer BL. New Zealand fisheries. A geographical perspective. Wellington: New Zealand Fishing Industry Board, 1986.

5 Occupational Health Task Force. The fishing industry. Review of occupational health problems in the fishing industry. Wellington: Department of Health, 1981.

6 Reilly MSJ. Mortality from occupational accidents to United Kingdom fishermen 1961-80. Br J Ind Med 1985;42:806-14.

7 Moore SRW. The morbidity and mortality of fishermen sailing from Grimsby in one year. Br J Ind Med 1969;26:25-46.

8 Schilling RSF. Trawler fishing: an extreme occupation. Proceedings of the Royal Society of Medicine 1966;59:405-10.

9 Schilling RSF. Hazards of deep-sea fishing. $\mathrm{Br} J$ Ind Med 1971;28:27-35.

10 Department of Statistics. New Zealand standard classification of occupations. Wellington: Department of Statistics, 1980. 
11 International Labour Office. International standard classification of occupations. Geneva: ILO, 1968.

12 Department of Statistics. 1980-1981 New Zealand census of fishing. Wellington: Department of Statistics, 1981.

13 World Health Organisation. Manual of the international statistical classification of diseases, injuries and causes of death. Geneva: WHO, 1977

14 Rothmans KJ, Boice JD. Epidemiologic analysis with a programmable calculator. Washington: National Institute of Health, 1979.

15 Fishing Industry Training Council. New Zealand deep water trawlers - an organisational needs analysis. Wellington: New Zealand Fishing Industry Board, 1987.

16 Fishing Industry Training Council. Deck safety-a workbook for fishermen aboard deepwater trawlers (accompanies educational

\section{An attempted suicide when hypoglycaemic}

The Guardian newspaper for 22 March $1989^{1}$ reported that "human insulin may hold risks for diabetics." The article focussed on the fact that human insulin (genetically engineered) may eliminate the symptoms and signs of hypoglycaemia such as sweating, paraesthesia, and palpitations. Many diabetics rely on the effects of a low blood sugar as part of the regulatory mechanism.

The Guardian article was based on the March edition of the Drug and Therapeutics Bulletin. ${ }^{2}$

\section{Case report}

A 46 year old man with a 35 year history of diabetes presented to his general practitioner. He complained of insomnia, irritability, depression, and emotional outbursts. This consultation took place shortly after the diabetic clinic of the local hospital changed him from beef to human insulin.

He was started on amitriptyline but there appeared to be little or no improvement. One of the authors (ELT), working in occupational medicine, knew of the history and was also aware of poor work performance that included poor memory capability and impaired concentration. In consultation with the general practitioner a referral was arranged to a local psychiatric hospital.

When he was interviewed by a psychiatrist (SPM) his history showed a recent episode of physical violence with suicidal ideas centred on the administration of an overdose of insulin. His mental state at the outpatient interview was normal. Admission was, however, arranged for full assessment and the differential diagnosis was depression or emotional lability owing to the uncontrolled diabetic state. A diagnosis of depression was not supported by the Beck depression inventory. During a five day in patient stay there was no evidence of psychiatric disorder but a consultant physican specialising in videotape). Wellington: New Zealand Fishing Industry Board, 1988.

17 Rodahl K, Vokac Z, Fugelli P, et al. Circulatory strain, estimated energy output and catecholamine excretion in Norwegian coastal fishermen. Ergonomics 1974;17:585-602.

18 Rodahl K, Vokac Z. Work stress in Norwegian trawler fishermen. Ergonomics 1977;20:633-42.

19 Chmielewski J, Zugas A, Nahsorki W. Evaluation of the efficiency of the circulatory system in the crew of a fishing ship during a 5 month cruise. Bull Inst Marit Trop Med Gdynia 1974;25:437-41.

Accepted 23 April 1990

endocrinology confirmed the finding of poorly controlled diabetes. The patient was, at this stage, kept on human insulin. At the time of discharge and a subsequent review his mental state was normal but his diabetic control remained erratic.

Two weeks after discharge he injected himself with insulin on three occasions over four hours. This was with definite suicidal intent associated with rage and frustration. He was promptly readmitted and dextrose was administered intravenously to correct the hypoglycaemia. After a review of the treatment for his diabetes a change to beef insulin took place. Since then he has been well, has performed his job to a good standard, and is studying hard for an Open University degree.

\section{Comment}

This man, who had no previous history of psychiatric illness, would appear to have suffered a profound impairment of his mental functioning that damaged his work performance. His domestic relations became strained and his behaviour threatened his own life. The perception of hypoglycaemia is important to diabetics although the mechanisms are not fully understood. It is well established that human insulin can compromise subjective awareness of hypoglycaemia.

All doctors should be aware of recent changes in insulin therapy when assessing psychiatric problems in diabetics.

E L TEASDALE
ICI Pharmaceuticals, Alderley House, Alderley Park,
Macclesfield, Cheshire SK10 4TF,
S P MCKEOWN
Altrincham Priory Hospital,
Cheshire WA15 ONX

1 Erlichman J. Human Insulin may hold risks for diabetics. The Guardian 1989 March 22:4(col 7-8).

2 Human insulin: an update. Drug and Therapeutics Bulletin. Vol 27. No 6. March 1989. 